\title{
Rectangular tank surface aerators: scale up criteria and energy conservation
}

\author{
${ }^{*}$ A. R. Rao and B. Kumar
}

Department of Civil Engineering, Indian Institute of Science, Bangalore, India

Received 3 May 2006; revised 19 August 2006; accepted 3 September 2006; available online 1 October 2006

\begin{abstract}
Surface aeration experiments were conducted in two types of rectangular tanks of aspect ratios i.e., length to width ratio (L/W) of 1.5 and 2 and developed simulation equations to correlate the oxygen transfer coefficient, $k$ and power number, $\mathrm{P}_{0}$ with a parameter governing theoretical power per unit volume $\mathrm{X}$. The parameter $\mathrm{X}$ is defined as equal to $\mathrm{F}^{4 / 3} \mathrm{R}^{1 / 3}$, where $\mathrm{F}$ and $\mathrm{R}$ are impellers' Froude and Reynolds numbers respectively). Results have shown that the $\mathrm{P}_{0}$ can not be simulated singularly with either Reynolds number, $\mathrm{R}$ or Froude number, $\mathrm{F}$, which results in scaleeffects; there appears to be a need to incorporate the effects of both $\mathrm{F}$ and $\mathrm{R}$. It was found that $\mathrm{P}_{0}$ is uniquely related to $\mathrm{X}$ for rectangular aeration tanks of both aspect ratios, however, such relationships are different depending upon the aspect ratios. It has been demonstrated that energy can be saved substantially if the aeration tanks are run at relatively higher input powers. It is also demonstrated that smaller sized tanks are more energy conservative and economical when compared to big sized tanks, while aerating the same volume of water, and at the same time by maintaining a constant input power in all the tanks irrespective of their size.
\end{abstract}

Key words: Froude number, oxygen transfer coefficient, power number, power per unit volume, Reynolds number, surface aerators, water and wastewater treatment

\section{INTRODUCTION}

Aerobic wastewater treatment uses microorganism to feed on waste in the water and convert them to sludge, carbon dioxide and water. To keep the process going, the wastewater needs to be aerated with oxygen. The two basic and widely used methods of aerating wastewater are: (1) to introduce air or pure oxygen into the wastewater body with diffusers generally called as bubble or diffused aerators and (2) to agitate the wastewater mechanically so as to promote the mass transfer of air from the atmosphere into the wastewater body, which is generally achieved by surface aerators. Surface aerators are a popular choice of aeration system because of their inherent simplicity and their competitive rate of oxygen transfer per unit of power input under actual aeration conditions. To design surface aerators in geometrically similar systems, one may require scale-up criteria for two basic parametersoxygen transfer rates and input power. Power consumption in surface aerators is generally interpreted as the Power number. Most scale-up studies in the

\footnotetext{
*Corresponding author, Email: ark@civil.iisc.ernet.in
}

Tel.: 0802293 2328; Fax: 08022932328 past for mixing rely solely upon the relationship between power number and Reynolds number. While this is probably adequate for the baffled system, unbaffled system need incorporation of Froude number in the correlation for power number (Rushton, 1952). It is advantageous to use unbaffled surface aerators, because they give rise to higher fluid-particle mass transfer rates for a given power consumption (Grisafi, et al., 1994; Rao and Jyothish, 1997), which is the paramount importance in designing aeration system. In the unbaffled tanks, existence of central vortex plays an important role in enhancing the mass transfer process (Johnson and Huang, 1956; Hsieh 1991). In the literature, innumerable references are available on unbaffled cylindrical and square tanks and apparently there is no information available dealing the issues of the basic design variables of rectangular tank surface aerators. The focus of this paper is to develop the scaleup criteria for oxygen transfer and power requirement (power number) in geometrically similar rectangular tank surface aerators and from there analyze the results with an objective of conserving energy while using the different sized aerators. The experiment explained in 


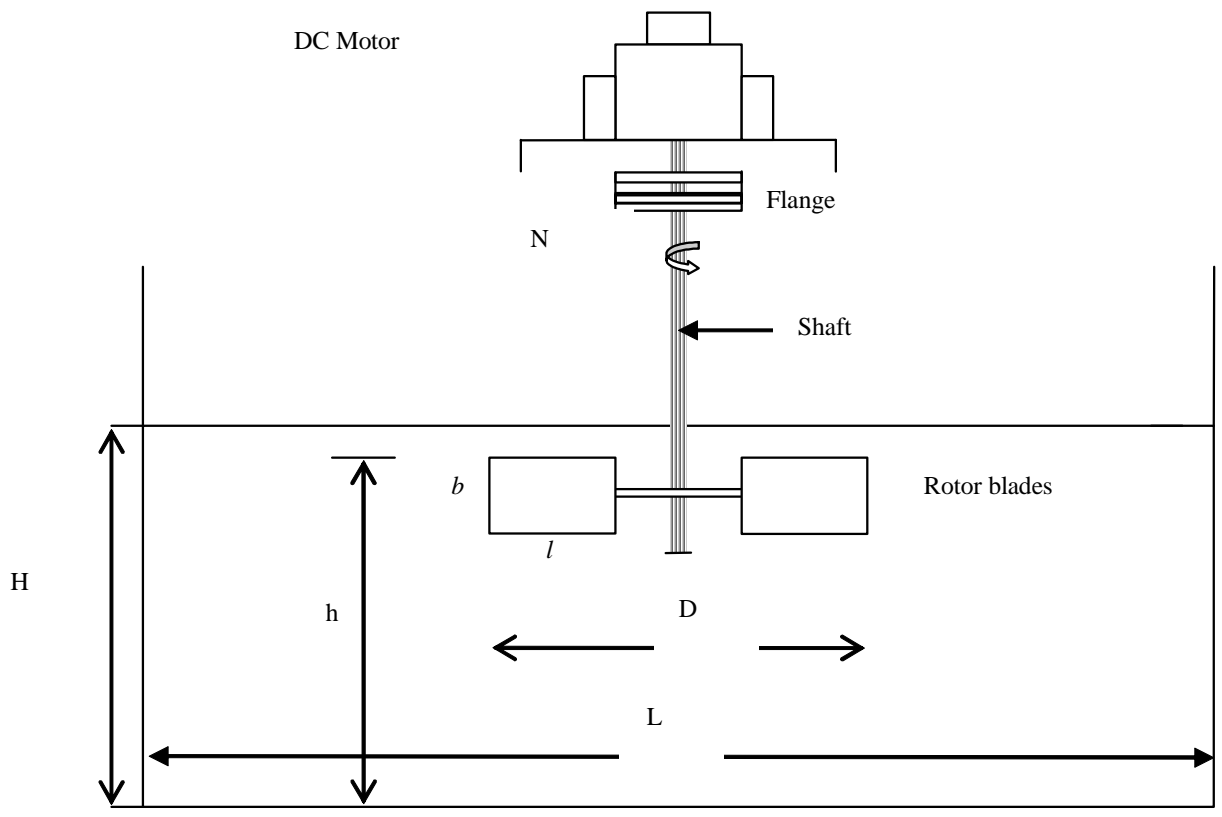

Fig. 1: Schematic diagram of a surface aerator

the present paper has been conducted at the Department of Civil Engineering, Indian Institute of Science, Bangalore in India during 2003-2005.

\section{MATERIALS AND METHODS}

Experiments were conducted in rectangular surface aerators of aspect ratios $\mathrm{L} / \mathrm{W}=1.5$ and 2. A typical surface aerator is shown in Fig. 1. The various geometric dimensions of the aerator are: A (cross-sectional area), $\mathrm{H}$ (water depth), $\mathrm{h}$ (distance between the horizontal bottom of the tank and the top of the blades) and D (diameter of the rotor). The rotor is fitted with six flat blades in symmetrical and evenly manner such that $b$ and $l$ are their linear dimensions. Rotor shaft is connected to a DC motor to rotate the rotor at desired speeds. The cross-sectional areas of tanks tested are $\mathrm{A}=1 \mathrm{~m}^{2}$, and $0.5184 \mathrm{~m}^{2}$ in each of the aspect ratios. Thus the four tanks were tested. Conditions of geometric similarity as suggested by Udaya et al. (1991) were maintained in all the four surface aerators i.e.

$\sqrt{ } A / D=2.88, H / D=1.0, l / D=0.3, b / D=0.24$ and $h / H=0.94$

Determination of Mass transfer coefficient

According to two-film theory (Lewis andWhitman, 1924), the oxygen transfer coefficient at $\mathrm{T}^{\circ} \mathrm{C}, K_{L} a_{T}$ may be expressed as follows.
$K_{L} a_{T}=\left[\ln \left(C_{s}-C_{0}\right)-\ln \left(C_{s}-C_{t}\right)\right] / t$

Where, the concentrations $C_{s} C_{0}$ and $C_{t}$ are dissolved oxygen (DO) in parts per million (ppm), $C_{s}=$ the saturation DO concentration at time tending to very large values, $C_{0}$ is at $\mathrm{t}=0$ and $C_{t}$ is at time $\mathrm{t}=\mathrm{t}$. The value of $K_{L} a_{T}$ can be obtained as slope of the linear plot between $\ln \left(C_{s}-C_{t}\right)$ and time $t$. The value of $K_{L} a_{T}$ can be corrected for a temperature other than the standard temperature of $20^{\circ} \mathrm{C}$ as $K_{L} a_{20}$, using the Vant- Hoff Arrhenins equation (WEF and ASCE, 1988):

$K_{L} a_{T}=K_{L} a_{20} \theta^{(T-20)}$

Where $\theta$ is the temperature coefficient 1.024 for pure water. The water in the aeration tank is deoxygenated by adding certain standard chemicals (WEF and ASCE, 1988) and the rotor is rotated at a desired speed. During the re-oxygenation process, DO measurements are made at regular intervals of time. The known values of $D O$ measurements in terms of $C_{t}$ at regular intervals of time $t$ (including the known value of $C_{0}$ at $t=0$ ) a linear line is fitted, by regression analysis of Eq. 2, between the logarithm of $\left(C_{\mathrm{s}}-C_{t}\right)$ and $t$, by assuming different but appropriate values of $C_{s}$ such that the regression that gives the minimum "standard error of estimate" is taken and thus the values of $K_{t} a_{T}$ and $C_{s}$ were obtained simultaneously. The values $K_{L} a_{20}$ are computed using 
Eq. 3 with $\theta=1.024$ as per the standards for pure water (WEF and ASCE, 1988). Thus the values of $K_{L} a_{20}$ were determined for different rotational rotor speeds $N$ in all of the geometrically similar tanks.

Determination of power availability to the shaft

The power available at the shaft was calculated as follows (Cook and Carr, 1947), which is given by:

$\mathrm{P}=\mathrm{I}_{2} \mathrm{~V}_{2}-\mathrm{I}_{1} \mathrm{~V}_{1}-\mathrm{R}_{\mathrm{a}}\left(\mathrm{I}_{2}{ }^{2} \mathrm{I}_{1}^{2}\right)$

Where, $I_{1}$ and $I_{2}$ are the current drawn by the motor at no loading (experiments without water, i.e., when the rotor is rotated freely in the air) and loading (when the rotor is rotated in water) respectively, $V_{1}$ and $V_{2}$ are the voltages at no loading and loading conditions respectively and $R_{a}$ is the armature resistance of the DC motor. By doing this way internal losses due to friction and such others can be eliminated to get an effective power available to the rotor shaft $\mathrm{P}$ can be computed from Eq. 4.

\section{Scale-up criteria}

Scaling-up is generally termed as to predict the process variables for any sizes based on the simulation equations developed from the laboratory experiments. From these results, large-scale design can be modeled from successful small-scale results avoiding process failure. The principle of similarity (Holland, 1964; Johnstone and Thring, 1957) together with the use of dimensionless groups is the essential basis of the scale-up of results. The scale-up of surface aeration systems can be divided into two categories: the scaleup of oxygen transfer process and the scale-up of power requirements, which are discussed later.

\section{Oxygen transfer coefficient}

The variables influencing the oxygen transfer coefficient at $20^{\circ} \mathrm{C}$ (i.e., $K_{L} a_{20}$ ), for a given shape of an aeration tank as shown in Fig. 1, are given by

$K_{L} a_{20}=\mathrm{f}\left(A, H, D, l, b, h, \mathrm{~N}, g, \rho_{\mathrm{a}}, \rho_{\mathrm{w}}, \mathrm{v}\right)$

Where, the first six are the geometric variables as shown in Fig 1. Rotational speed of the rotor with six flat blades is $\mathrm{N}$, g is the acceleration due to the gravity, ? is the kinematic viscosity of water and $\rho_{\mathrm{a}}$ and $\rho_{\mathrm{w}}$ are the densities of air and water respectively. Eq. 5 (Rao, 1999) may be expressed in terms of nondimensional parameters as follows:

$k=\mathrm{f}\left(\sqrt{ } A / D, H / D, l / D, b / D, h / D, \rho_{\mathrm{a}} / \rho_{\mathrm{w}}, \mathrm{R}, \mathrm{F}\right)$

Where, $k=K_{L} a_{20}\left(v / g^{2}\right)^{1 / 3}$ is the non-dimensional oxygen transfer coefficient, $\mathrm{R}=\mathrm{ND}^{2} / \mathrm{v}$ is called Reynolds number and $\mathrm{F}=\mathrm{N}^{2} \mathrm{D} / \mathrm{g}$ is the Froude number. It can be expressed also as (Rao, 1999; Rao, et al., 2004):

$k=\mathrm{f}\left(\sqrt{ } A / D, H / D, l / D, b / D, h / D, \rho_{\mathrm{a}} / \rho_{\mathrm{w}}, X\right)$

Where $X=F^{4 / 3} R^{1 / 3}$ is a parameter governing the theoretical power per unit volume.

In Eq. 7, the parameter $\rho_{\mathrm{a}} / \rho_{\mathrm{w}}$ is assumed as invariant; hence it can be eliminated from the analysis. The first five non-dimensional parameters represent the "geometric-similarity" of the system and the last parameter represents the dynamic-similarity. When the geometric similarity conditions are maintained, the functional relationship represented by Equation 7 is reduced to a function of dynamic similarity (Rao, 1999) for any shape of aeration tank.

$k=\mathrm{f}(X)$

The experimental data expressed in terms of $\mathrm{X}=F^{4 /}$ ${ }^{3} R^{1 / 3}$ and $k=K_{L} a_{y_{0}}\left(/ g^{2}\right)^{1 / 3}$ are plotted in Fig 2 . It is quite interesting to note that the each set of data points pertaining to the given aspect ratio $(1: 1.5$ or $1: 2)$ of the rectangular tank fall very uniquely on a single curve. The equations governing such simulations respectively for aspect ratios $1: 1.5$ and $1: 2$ can be expressed by the following equations:

$$
\begin{aligned}
& k_{r 1.5}=\left\{0.701 \exp \left[0.19 X^{0.25}\right]+8.035-7.955 \exp \right. \\
& \left.\left[-1.85(X-0.02)^{2}\right]\right\} 10^{-6} \sqrt{X}
\end{aligned}
$$

$k_{r 2}=\left\{0.6275 \exp \left[0.5 X^{0.03}\right]+21.085-20.955 \exp \right.$

$\left.\left[-1.85(X-0.02)^{2}\right]\right\} 10^{-6}$

Where, $\mathrm{k}_{\mathrm{r} 1.5}$ and $\mathrm{k}_{\mathrm{r} 2}$ is the non-dimensional oxygen transfer coefficient of rectangular tanks of aspect ratios $\mathrm{L} / \mathrm{W}=1.5$ and 2 respectively. 


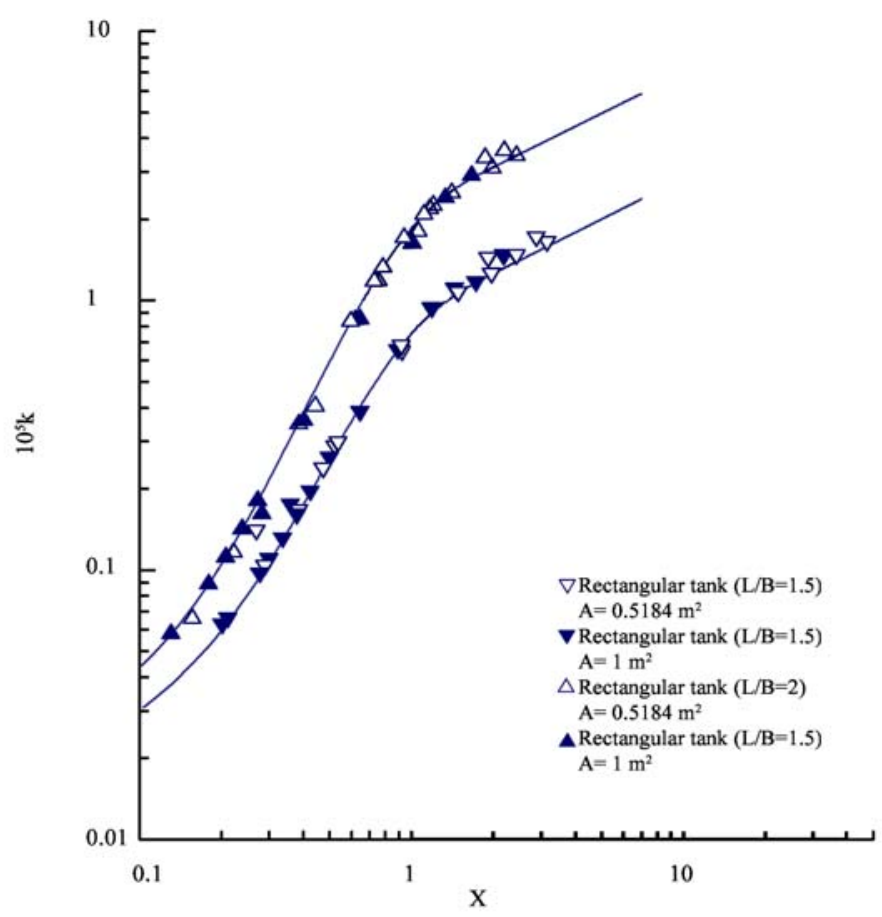

Fig. 2: Simulation equation correlating oxygen transfer coefficient with theoretical power per unit volume

\section{Power number}

The usage of power in mass transfer operations is very important while judging the performance of an aerator. The hydrodynamic conditions of surface aeration system can be characterized by interpreting power consumption of the impeller. Assuming the forces that may act on a fluid element in a tank during agitation are the viscous force $\mathrm{F}_{V}$, drag force on impeller $\mathrm{F}_{D}$, and gravity force $\mathrm{F}_{G}$, each of which can be expressed with characteristic quantities associated with the agitating system. The viscous force can be represented by the Newton's laws of viscosity as $\mathrm{F}_{V}=\mu\left(\frac{\partial u}{\partial y}\right) A$. It can be assumed (Perry et al., 1984) that the average velocity gradient is proportional to agitation speed $N$ and the area $A$ is to $\mathrm{D}^{2}$, which results $\mathrm{F}_{V} \sim \mu \mathrm{ND}^{2}$. The drag force $F_{D}$ can be characterized in an agitating system as (Lee, 1992), $F_{D} \sim \mathrm{P} / \mathrm{ND}$ and gravity force, $\mathrm{F}_{G} \sim \rho \mathrm{gD}^{3}$. The summation of all forces gives the inertial force, $\mathrm{F}_{I}$ $\sim \rho \mathrm{D}^{4} \mathrm{~N}^{2}$ in an agitated system, as $\mathrm{F}_{I}=F_{D}+\mathrm{F}_{V}+\mathrm{F}_{G}$. It can be simplify as $F_{D} / \mathrm{F}_{I}+\mathrm{F}_{V} / \mathrm{F}_{I}+\mathrm{F}_{G} / \mathrm{F}_{I}=1$. First term is called as power number $\left(\mathrm{P}_{0}\right)$ and relates the drag force to the inertial force and it is equal to $\mathrm{P}_{0}=\mathrm{P} / \rho$ $\mathrm{N}^{3} \mathrm{D}^{5}$. Second and third terms are well known and are called as Reynolds (R) and Froude number (F) respectively. Above analysis is showing that the hydrodynamics characteristics of an agitated system can be represented by these three numbers, $\mathrm{P}_{0}, \mathrm{R}$ and F. In general, as given in the literature (Rushton, 1952; Maise, 1970), these numbers can be expressed as follows:

$$
\mathrm{P}_{\mathrm{O}}=\mathrm{f}(\mathrm{R}, \mathrm{F})
$$

While adopting either the Reynolds criterion or the Froude criterion, scale effects are bound to appear, as shown in Figs 3a and 3b, because neither criterion can uniquely represent the power number of the surface aerators. In other words, power number is different in different sized aerators for a given value of either the Reynolds number or the Froude number even though all the tanks are geometrically similar. It may be also noted that it is impossible to maintain a constant Reynolds or Froude number while varying the Froude or Reynolds number in geometrically similar systems, when the same fluid is used in both the systems. 
Rectangular tank surface...
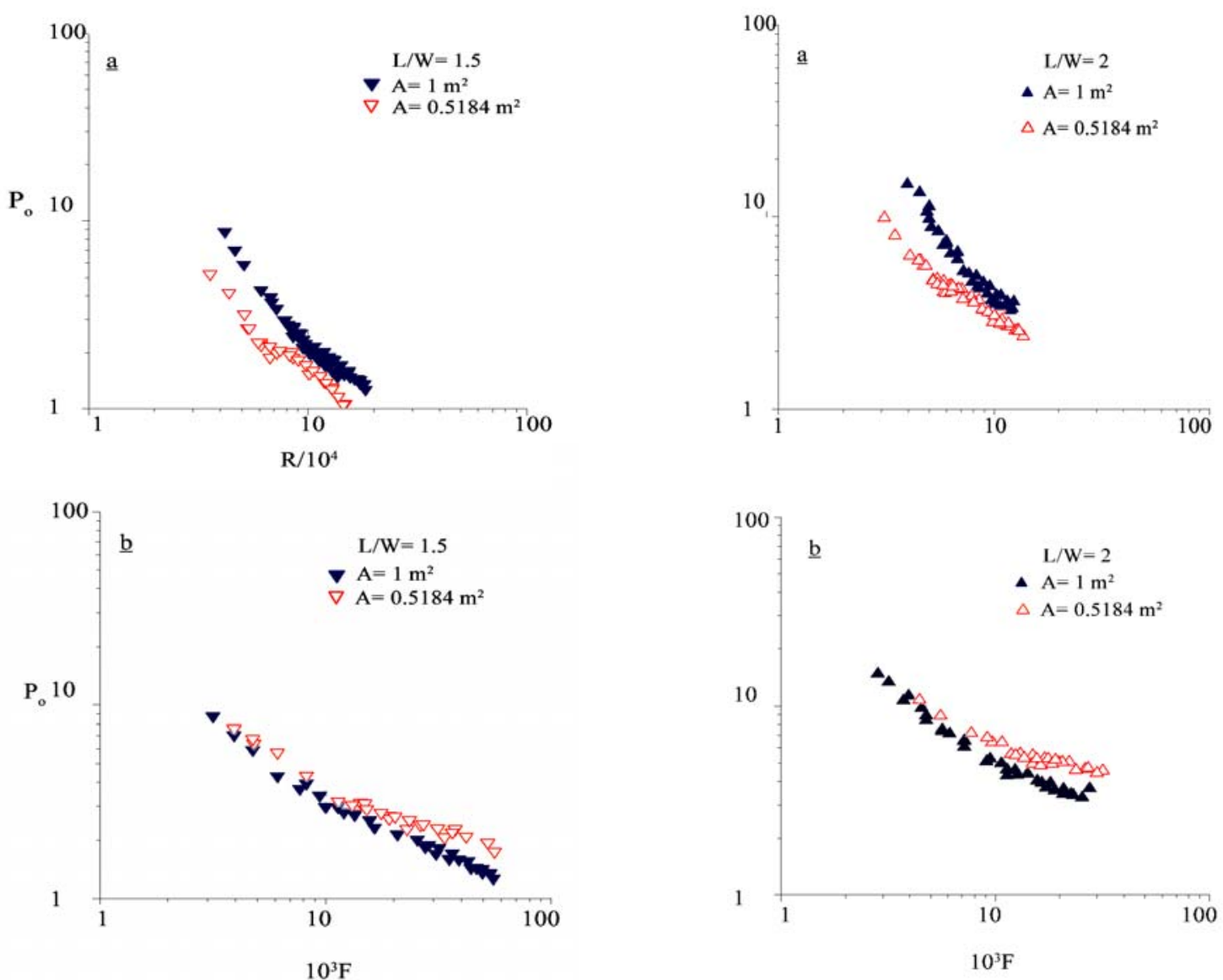

Fig. 3: Scale effects in simulation of Power number (a) With Reynolds number criterion and (b) With Froude number criterion

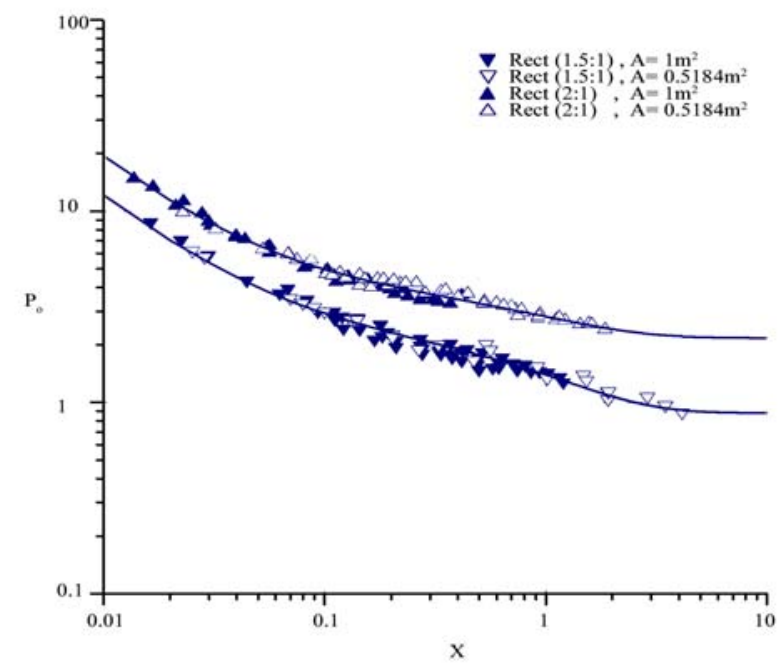

Fig. 4: Simulation equation relating power number with theoretical power per unit volume 
As discussed above, the parameter $\mathrm{X}$ contains both Reynolds number and Froude number and it is expressed as $X=F^{4 / 3} R^{1 / 3}$, So the experimental data expressed in terms of power number $\left(\mathrm{P}_{0}\right)$ and $\mathrm{X}$ are plotted in Fig 4. It is of interest to observe that for geometrically similar systems rectangular tank surface aerators, power number, $\mathrm{P}_{0}$ and $\mathrm{X}$ is uniquely related. Experimental data falls on a unique curve. Such a simulation curve is size independent, but different for different aspect ratios. The equations governing the simulation curves can be described by the following two equations:

$\mathrm{P}_{0}=0.87+0.1 / \mathrm{X}+1.16 \mathrm{e}^{-\mathrm{X}}$

[Rectangular Tank of L/W =1.5]

$\mathrm{P}_{0}=2.16+0.16 / \mathrm{X}+1.36 \mathrm{e}^{-\mathrm{X}}$

[Rectangular Tank of $\mathrm{L} / \mathrm{W}=2$ ]

\section{RESULTS}

The relations developed in Eqs. 9 and 10 and 12 and 13 (Figs. 2 and 4) for $k$ with $\mathrm{X}$ and $\mathrm{P}_{0}$ with $\mathrm{X}$ respectively are analyzed for design purposes with an objective of searching the conditions leading to conserve the energy consumption, while choosing different sized aerator to aerate a given volume of water. It should be also mentioned here that these design curves are useful not only for scale-up but also helpful in choosing the right sized rectangular tank and appropriate dynamic conditions. Such design implications are demonstrated as follows:

Example. Analyze the energy requirement to re-aerate $1 \mathrm{~m}^{3}$ volume of water by a single tank and a number of smaller sized tanks of equal volume, when each tank is subjected to a constant installed input power $(\mathrm{P})$ to the shaft. The rotor is rotated until DO concentration, $\mathrm{C}_{\mathrm{t}}$, attains $80 \%$ of the saturation value. The initial DO concentration $\mathrm{C}_{0}=0$ at $\mathrm{t}=0$ and water temperature is assumed as constant at $25^{\circ} \mathrm{C}$. Solution: Four different sized rectangular tanks $\left(1 \mathrm{~m}^{3}, 0.5 \mathrm{~m}^{3}, 0.25 \mathrm{~m}^{3}\right.$ and $\left.0.1 \mathrm{~m}^{3}\right)$ of aspect ratios 1.5 and 2 are taken to analyze their energy consumption to aerate $1 \mathrm{~m}^{3}$ of water at constant input power $(\mathrm{P})$, such that the numbers of tanks of each size are respectively 1, 2, 4 and10.Step 1: Geometrical parameters of the typical surface aerator as shown in Fig. 1 can be worked out by the geometric similarity condition as given in Eq. 1, step 2: The problem is solved for different assumed values of power, $\mathrm{P}=50,100,200$ and 300 watts. As P, D and volume of water are known; $\mathrm{N}$ can be calculated from Eqs. 12 and 13 for aspect ratios 1.5 and 2 respectively by trial and error method and there from $\mathrm{X}$ and $\mathrm{P}_{0}$ can be calculated.

Step 3: The oxygen transfer coefficient, $k$ can be computed from Equation 9 and 10, because $\mathrm{X}$ is known from the previous step or can be read out from Fig 2. Step 4: The value of $\mathrm{K}_{\mathrm{L}} \mathrm{a}_{20}$ can be computed from $k=K_{L} a_{20}\left(v / g^{2}\right)^{1 / 3}$, and $K_{\mathrm{L}} \mathrm{a}_{\mathrm{T}}$ from Eq. 3 .

Stpe 5: Time trequired to achieve $80 \%$ of saturation value is calculated from Eq. 2.

Step 6: Energy is defined as the product of power and time. To aerate $1 \mathrm{~m}^{3}$ of water, it is required to employ 10 tank of $0.1 \mathrm{~m}^{3}, 4$ tanks of $0.25 \mathrm{~m}^{3}, 2$ tanks of $0.5 \mathrm{~m}^{3}$ and one tank of $1 \mathrm{~m}^{3}$ capacities. So Energy required to re-aerate the $1 \mathrm{~m} 3$ of water in multiple tanks is calculated as the product of total power (number of tank $\mathrm{x}$ power consumed) and time.As shown in Figs. 5 and 6, smaller sized tanks are consuming less energy to re aerate the same volume of water, with less time for re aeration (Figs. 5c and 6c), when compared to bigger sized tanks. One more interesting conclusion can be drawn from Figs 5 and 6 is such that even for a given size of tanks, higher the input power $P$, lesser the energy requirements to aerate the same volume of water, which suggests that energy can be saved substantially when the aerators of a given size are run at higher input powers (Figs. 5d and 6d). Also it can be observed that in a given size of aerator $\mathrm{K}_{\mathrm{L}} \mathrm{a}_{20}$ increases as input power increases (Figs. 5a and 6a) whereas the rotor speed is also more (Figs. 5b and 6b). It is of our interest to know how much saving of energy can be achieved by using smaller sized tanks or loss of energy when bigger sized tanks are employed in aeration process to re-aerate the same volume of water. As shown in Fig. 7, by using smaller sized tanks, energy savings can be as high as about $80 \%$ and $64 \%$ in rectangular tank of aspect ratios 1.5 and 2 respectively when lower input power is given to each tank.

\section{DISCUSSION AND CONCLUSION}

This paper develops the simulation criteria connecting the three major parameters of oxygen transfer coefficient, $k$ and power number, $\mathrm{P}_{0}$ and a parameter governing the theoretical power per unit volume, $\mathrm{X}\left(=\mathrm{F}^{4 / 3} \mathrm{R}^{1 / 3}\right)$ in geometrically similar rectangular tanks of two aspect ratios (L/W=1.5 and 2). Simulation equations, thus developed are useful in scaling up the present results for the higher sizes. 


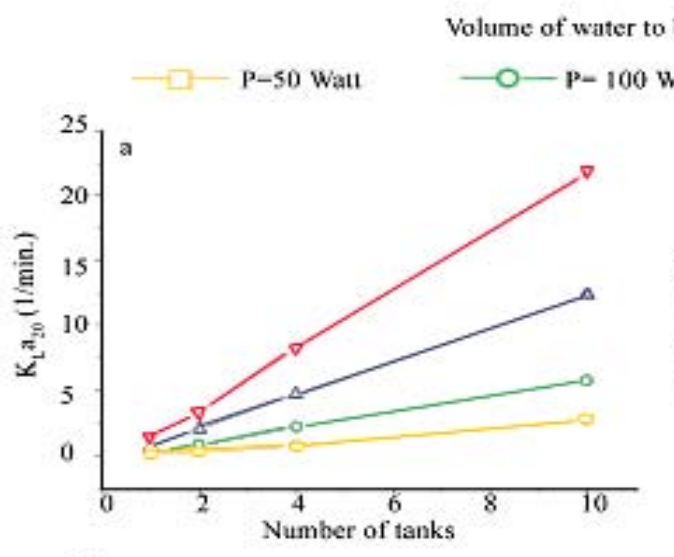

be acrated $-1 \mathrm{~m}^{3}$
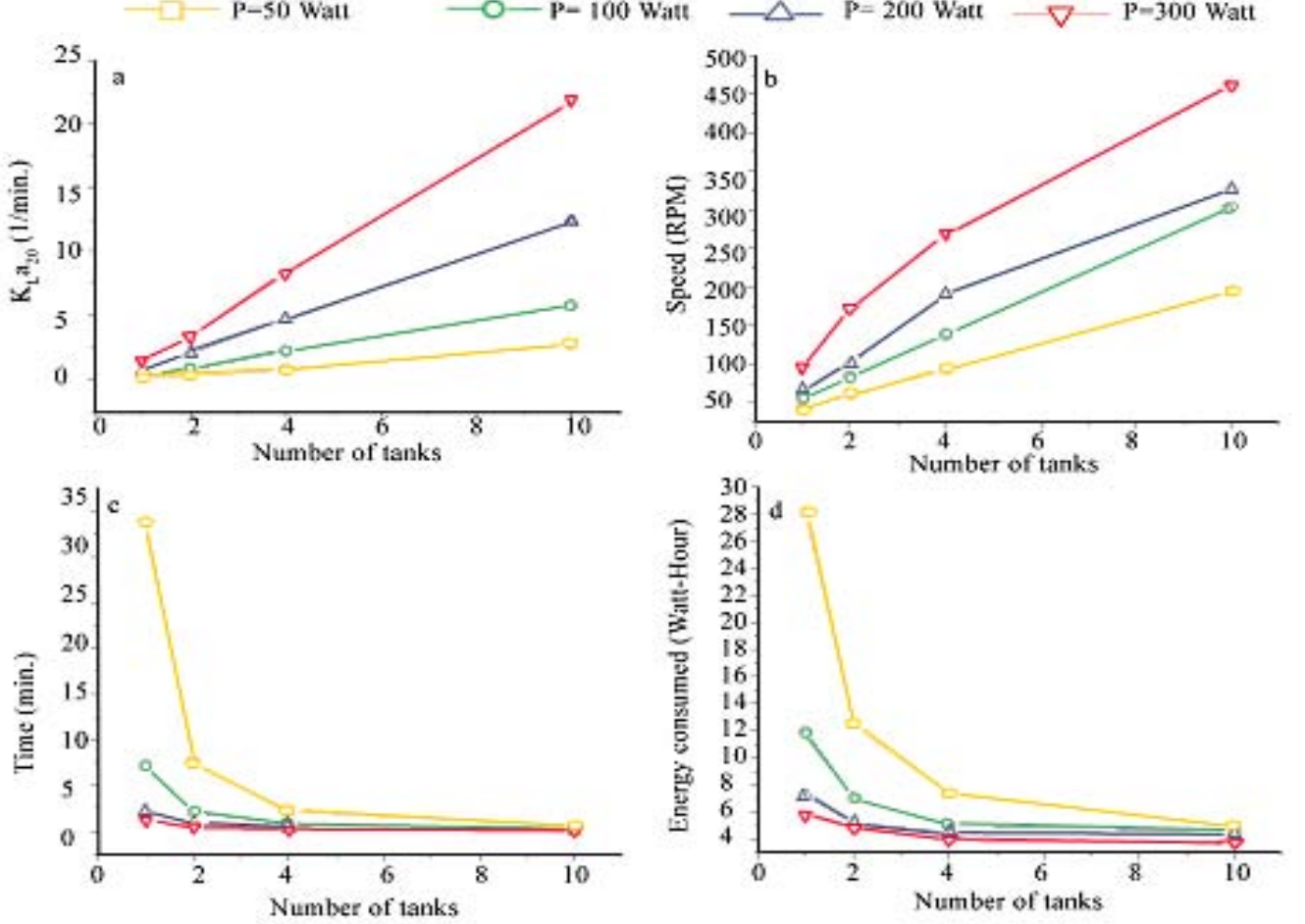

Tanks used in the analysis $1 \mathrm{~m}^{3}$ tank, $0.5 \mathrm{~m}^{3}$ tank, $025 \mathrm{~m}^{3}$ tank and $0.1 \mathrm{~m}^{3}$ tank

Fig. 5: Calculated design parameters of rectangular tank $(\mathrm{L} / \mathrm{W}=1.5)$ surface aerator at constant power

It has been found that either Reynolds (R) or Froude (F) similitude is insufficient to simulate $\mathrm{P}_{0}$. Based on the experiments, it is concluded that $\mathrm{P}_{0}$ is uniquely related to $\mathrm{X}$. Equations governing $\mathrm{P}_{0}$ and $\mathrm{X}$ and $k$ and $\mathrm{X}$ have been also developed in the present paper.

Design procedures for designing the rectangular tank surface aerator have been demonstrated. It has been found that at constant input power, employing smaller sized tanks are more energy conservative than using a big sized tank, while aerating the same volume of water, thus energy saving by using smaller sized tanks is very substantial. Besides this, time for reaeration is considerably reduced while using smaller sized tanks when compared to bigger sized aeration tanks to aerate the same volume of water.

\section{NOTATION}

The following symbols are used in this paper: $A=$ cross-sectional area of an aeration tank; $b$ = width of the blade;
$C_{0}=$ initial concentration of dissolved oxygen at time $t=0(\mathrm{ppm})$;

$C_{s}=$ saturation value of dissolved oxygen at test conditions (ppm);

$C_{t}=$ concentration of dissolved oxygen at any time $t$ (ppm);

$D=$ diameter of the rotor;

$F=N^{2} D / g$, Froude number;

$\mathrm{F}_{\mathrm{D}}=$ drag force;

$\mathrm{F}_{\mathrm{G}}=$ gravity force;

$\mathrm{F}_{\mathrm{L}}=$ inertial force

$\mathrm{F}_{\mathrm{v}}=$ viscous force;

$g=9.81 \mathrm{~m} / \mathrm{s}^{2}$, acceleration due to gravity;

$H=$ depth of water in an aeration tank;

$h=$ distance between the top of the blades and the horizontal floor of the tank;

$\mathrm{I}_{1}, \mathrm{I}_{2}=$ input current at no load and loading conditions respectively;

$k=K_{L} a_{20}\left(v / g^{2}\right)^{1 / 3}$, non-dimensional oxygen transfer coefficient; 
$K_{L} a_{T}=$ overall oxygen transfer coefficient at room temperature $T^{\circ} \mathrm{C}$ of water;

$K_{L} a_{20}=$ overall oxygen transfer coefficient at $20^{\circ} \mathrm{C}$;

$\mathrm{L}=$ length of the surface aerator;

$l=$ length of the blade $(\mathrm{L})$;

$N$ = rotational speed of the rotor with blade;

$\mathrm{P}=$ power available to the rotor shaft;

$\mathrm{P}_{0}=\mathrm{P} / \mathrm{\rho N}^{3} \mathrm{D}^{5}$, Power number;

$R=N D^{2} / v$, Reynolds number;

$\mathrm{v}=$ characteristics velocity;
$V=$ volume of water in an aeration tank;

$\mathrm{R}_{\mathrm{a}}=$ armature resistance of DC motor;

$\mathrm{V}_{1}, \mathrm{~V}_{2}=$ input voltage at no load and loading conditions respectively;

$X=F^{4 / 3} R^{1 / 3}=$ theoretical power per unit volume

parameter;

$\theta=1.024$, constant for pure water;

$v=$ kinematic viscosity of water;

$\rho=$ mass density of water.



be acrated $-1 \mathrm{~m}^{3}$
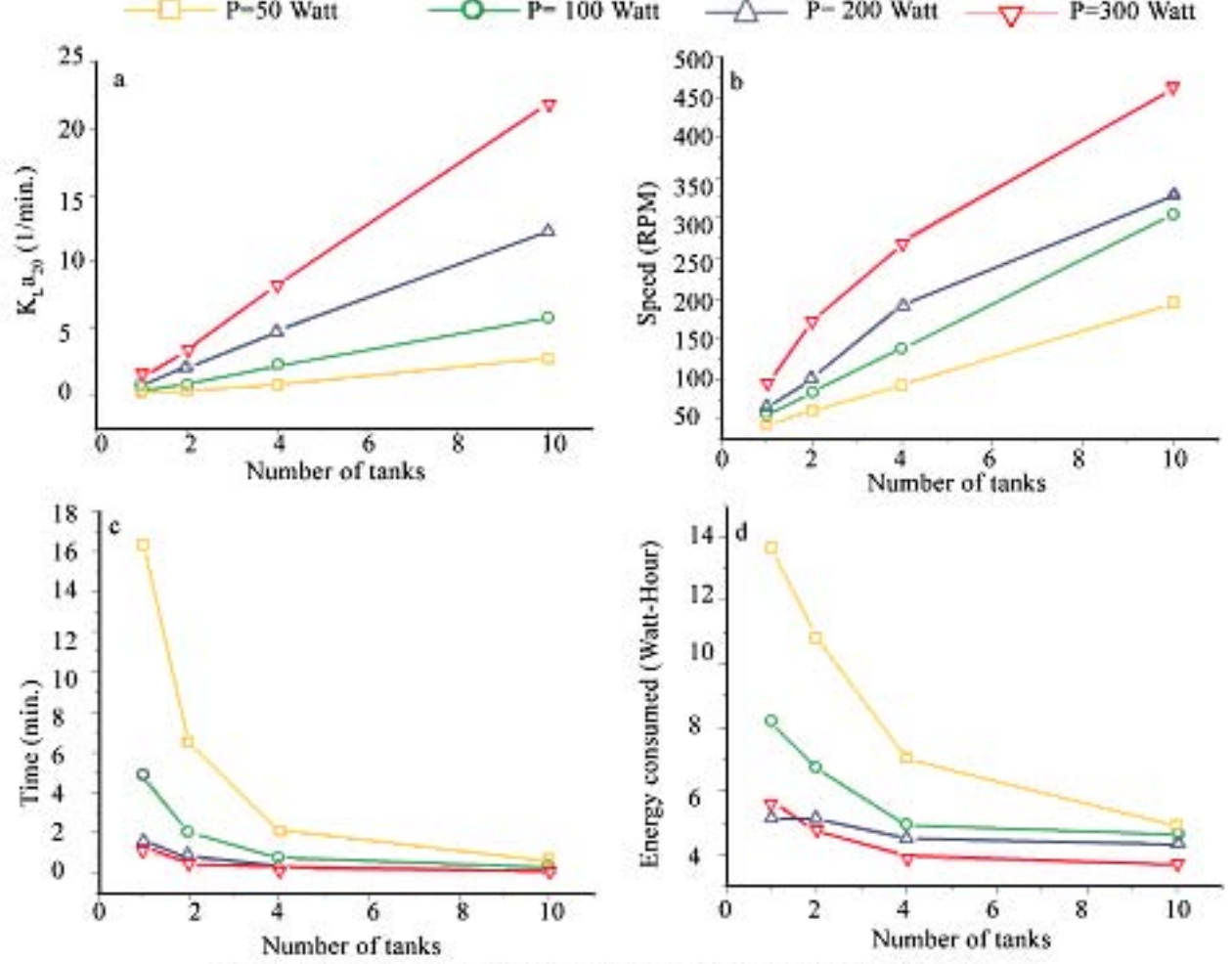

Tanks used in the analysis $1 \mathrm{~m}^{3}$ tank, $0.5 \mathrm{~m}^{3}$ tank, $025 \mathrm{~m}^{3}$ tank and $0.1 \mathrm{~m}^{3}$ tank

Fig. 6: Calculated design parameters of rectangular tank $(\mathrm{L} / \mathrm{W}=2)$ surface aerator at constant power

\section{REFERENCES}

Cook, A. L. and Carr, C. C., (1947). Elements of electrical engineering. $5^{\text {th. }}$ Ed. Wiley. New York.

Grisafi, F., Brucato, A. and Rizzuti, L., (1994). Solid liquid mass transfer coefficients in mixing tanks: influence of side wall roughness. Instn Chem. Engn Symp. Ser., 136, 571578.

Holland, F., (1964). Scale-up in chemical engineering, Chem. Proc. Eng., 45, 1214.

Hsieh, Ch. Ch., (1991). Estimating volatilization rates and gas/liquidmass transfer coefficients in aeration systems.
Ph.D. thesis, Dept. of Civil Engg., University of California, Los Angeles, USA.

Johnstone, R. E. and Thring, M. W., (1957). Pilot plants, models and scale-up methods in chemical engineering. New York, McCraw-Hill Book Company, Inc.

Johnson, A. I. and Huang, Ch. J., (1956). Mass transfer studies in an agitated vessel. AICHE J., 2, 412-419.

Lee James, M., (1992). Biochemical engineering, Prentice Hall. Lewis, W. K. and Whitman, W. G., (1924). Principles of gas absorption. Ind .Eng. Chem., 16 (12), 1215-1220. 
Maise G., (1970). Scaling methods for surface aerators. J. sanitary engg. Division, ASCE SA5, 1079-1083.

Perry, R. H., Green, D.W. and Malony, J.O., (1984). Perry's Chemical Engineers' Handbook, 6 ${ }^{\text {th. }}$ Ed., McGraw-Hill, New York.

Rao, A. R. K., (1999). Prediction of reaeration rates in square, stirred tanks. Journal of Environmental Engineering, ASCE, 125 (3), 215-233.

Rao, A. R. K., Bharathi, B.V., Laxmi and Subba Narasiah, K., (2004). Simulation of oxygen transfer rates in circular aeration tanks. Water Qual. Res. J. Canada, 39 (3), 237244.

Rao, A. R. K. and Jyothish. S., (1997). Oxygen transfer in circular surface aeration tanks with and without Baffles, The International Conference on Industrial Pollution and
Control Technologies, held at Jawaharlal Nehru Technological University (JNTU), Hyderabad, India, Nov. 17-19.

Rushton J. H., (1952). Applications of fluid mechanics and similitude to scale-up problems-part1. Chem. Engg. Progress. 48, 33-38.

UdayaSimha L., Shrma K. V. N. S. and Rao A. R. K., (1991). Effect of geometrical parameters for overall Oxygen transfer coefficient. Proc. Symp. On Environmental Hydraulics, University of Honkong, 1577-1581.

WEF and ASCE Manual of practice for water pollution control (1988). Aeration a waste water treatment process. Water Environment Federation, Alexandria, Va., and ASCE, New York.

\section{AUTHOR(S) BIOSKETCHES}

Rao, A. R., Ph.D. is an associate professor in the Department of Civil Engineering, Indian Institute of Science, Bangalore, India. Email: ark@civil.iisc.ernet.in

Kumar, B., M.E. is a Ph.D. Research Student in Department of Civil Engineering at Indian Institute of Science, Bangalore, India. Email: bimk@civil.iisc.ernet.in

This article should be referenced as follows:

Rao, A. R. and Kumar, B. (2006). Rectangular tank surface aerators: scale up criteria and energy conservation. Int. J. Environ. Sci. Tech., 3 (4), 425-433 